\title{
Removal of pesticide toxicity by cysteine-capped Ag nanoparticles and study of their adsorption kinetics
}

This article was published in the following Dove Press journal: International Journal of Nanomedicine

\author{
Aditi Singhal' \\ Mary Laura Lind ${ }^{2}$ \\ 'School of Engineering and Applied \\ Science, Ahmedabad University, \\ Ahmedabad, Gujarat, India; ${ }^{2}$ School \\ for Engineering of Matter, Transport \\ and Energy, Arizona State University, \\ Tempe, AZ, USA
}

\begin{abstract}
A new method has been developed for one-step synthesis of cysteine-capped Ag nanoparticles. The particles have been characterized by several techniques, including ultravioletvisible spectroscopy, infrared spectroscopy, X-ray diffraction, scanning electron microscopy, and transmission electron microscopy. The interaction of these nanoparticles has been seen with two pesticides, namely, chlorpyrifos and malathion, which are major water pollutants.
\end{abstract}

Keywords: Ag nanoparticles, adsorption, chlorpyrifos, malathion, kinetic models

\section{Introduction}

Water toxicity has been a major problem that the world is facing today. One of the main compounds increasing the toxicity of water is pesticide, which is causing great threat to the inhabitants of earth. ${ }^{1}$ Many methods have been developed for the removal of these pesticides, but metal nanoparticles are being widely used in this area due to their unique properties, such as small particle sizes, large surface-to-volume ratio, and the ease with which they can be attached onto the solid matrices for the treatment of waste water. ${ }^{2}$ Pesticides such as chlorpyrifos and malathion are the two major water pollutants. ${ }^{3,4}$ Chlorpyrifos, $O, O$-diethyl- $O$-(3,5,6-trichloro-2-pyridyl) phosphorothioate $\left(\mathrm{C}_{9} \mathrm{H}_{11} \mathrm{C}_{13} \mathrm{NO}_{3} \mathrm{PS}\right)$, an organophosphate insecticide, is a very common one and highly used active ingredients for pest control worldwide. Malathion, $S$-1,2-bis(ethoxycarbonyl) ethyl $O, O$-dimethyl phosphorodithioate, causes child anemia, kidney failure, leukemia, and human birth defects and DNA abnormalities. In this article, we report synthesis and complete characterization of cysteine-capped Ag nanoparticles. The aim of this article is to find the affinity of these Ag nanoparticles toward the two pesticides.

\section{Materials and methods}

L-Cysteine, ethanol, $\mathrm{AgNO}_{3}$, tert-butylamine-borane complex (Sigma Chemical, St Louis, MO, USA; Fisher Scientific, Hampton, NH, USA), and the Nanopure water (18 M $\Omega$ ) were used for the experiments. Ultraviolet-visible (UV-Vis) spectrometry was performed using an Agilent 8453 UV-VIS-NIR Photodiode Array System (Agilent Technologies, Santa Clara, CA, USA). Fourier transform infrared spectroscopy (FT-IR) was performed using a Nicolet Magna 850 FT-IR spectrometer (Thermo Fisher Scientific, Waltham, MA, USA) in mid-IR range. Powder X-ray diffraction (XRD) pattern was obtained on a Philips X'PERT-MPD (PANalytical, Boulder, CO, USA), with $\mathrm{CuK} \alpha$ between $10^{\circ}$ and $80^{\circ}$. Scanning electron microscopy (SEM) was performed on a FEI XL40 Sirion FEG digital scanning microscope (FEI, Hillsboro, OR, USA). 
Transmission electron microscopy (TEM) analysis was carried out using a FEI-Technai G2 Sphera microscope with field emission gun at $200 \mathrm{kV}$, point resolution at $0.27 \mathrm{~nm}$, and a line resolution at $0.14 \mathrm{~nm}$. Cysteine-capped $\mathrm{Ag}$ nanoparticles were prepared by a simple one-step synthesis process, which has already been reported. ${ }^{5}$ One ppm solution of pesticide (chlorpyrifos/malathion) and $7 \mathrm{ppm}$ solution of cysteinecapped Ag nanoparticles (concentration calculated from the calibration plot) were prepared. Using these, two different solutions were prepared, solution I contains $2 \mathrm{~mL}$ (7 ppm) of Ag solution $+2 \mathrm{~mL}$ of water and solution II contains $2 \mathrm{~mL}$ (7 ppm) of Ag solution $+2 \mathrm{~mL}$ (1 ppm) of pesticide solution. Absorbance of both these solutions was recorded. The absorbance of solution II was recorded after every $20 \mathrm{~min}$, and the change in the absorbance value was noted.

\section{Results and discussion}

The synthesis method used herein resulted in uniformly shaped Ag nanoparticles with a mean diameter of $9 \mathrm{~nm}$,
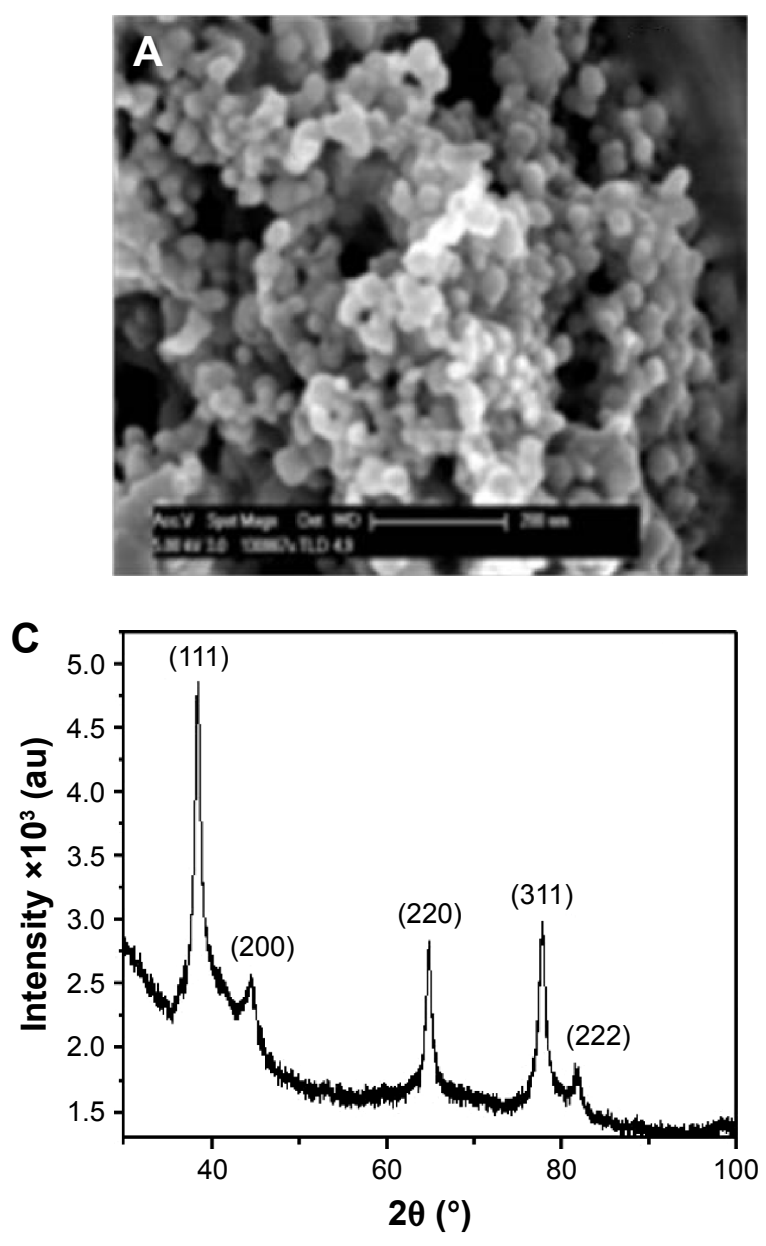

Figure I (A) Scanning electron microscopy, (B) transmission electron microscopy, particles.

Abbreviation: au, arbitrary units. which can be seen from the SEM (Figure 1A) and TEM (Figure 1B) images. XRD analysis of the particles revealed a face-centered cubic structure (Figure 1C). The IR spectrum of $\mathrm{Ag}$ indicated clearly the formation of thiol-silver bond, marked by the disappearance of $2,500 \mathrm{~cm}^{-1}$ peak in free cysteine which is due to the thiol group. This peak is absent in the IR spectrum of $\mathrm{Ag}$ nanoparticles. It is due to the formation of S-Ag bond replacing the thiol $(\mathrm{S}-\mathrm{H})$ bond in cysteine (Figure 1D).

Figure 2A shows the changes in the optical absorption spectrum of Ag nanoparticles upon exposure to $1 \mathrm{ppm}$ chlorpyrifos at different intervals of time. Trace at $0 \mathrm{~min}$ is absorption spectrum of solution I having an absorption maximum of $430 \mathrm{~nm}$ and second trace from top was the absorption spectrum of solution II. The subsequent traces of solution II were taken at 20 min intervals of time. Arrow represents the decrease in absorbance with time. As can be seen from the spectra, the plasmon absorption of Ag nanoparticles at $430 \mathrm{~nm}$ decreased in intensity with time.
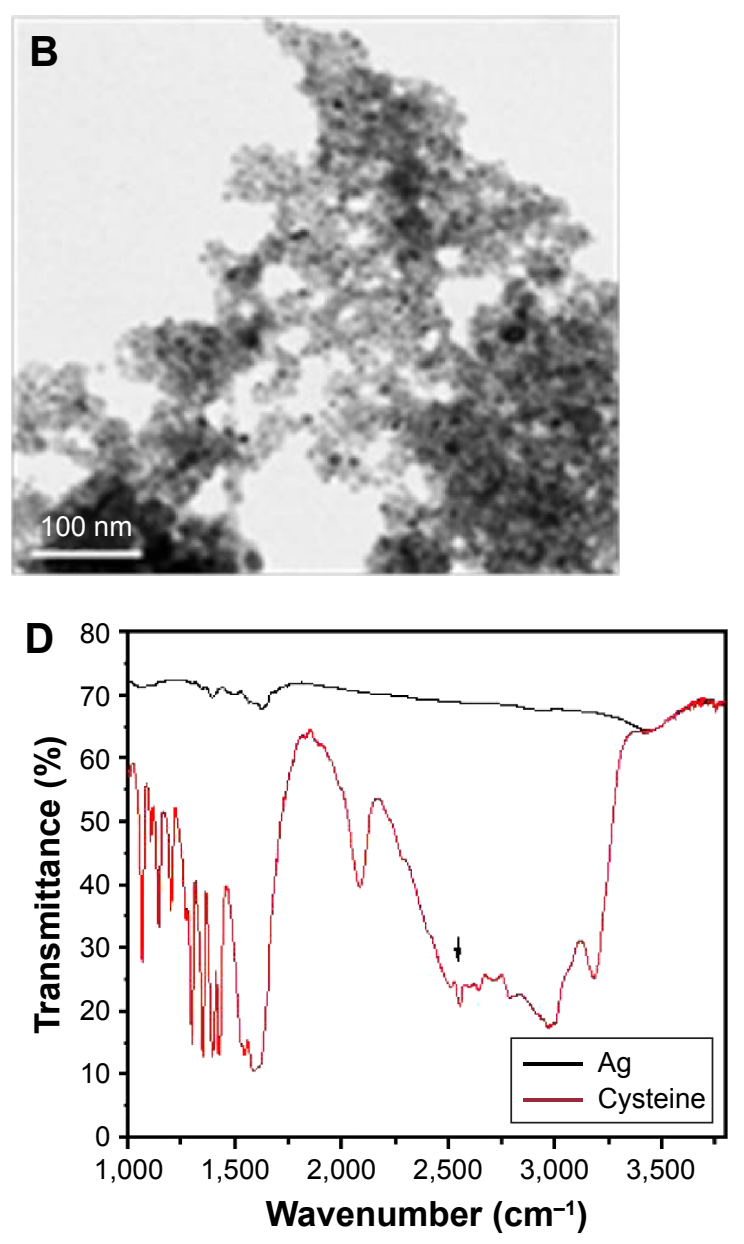

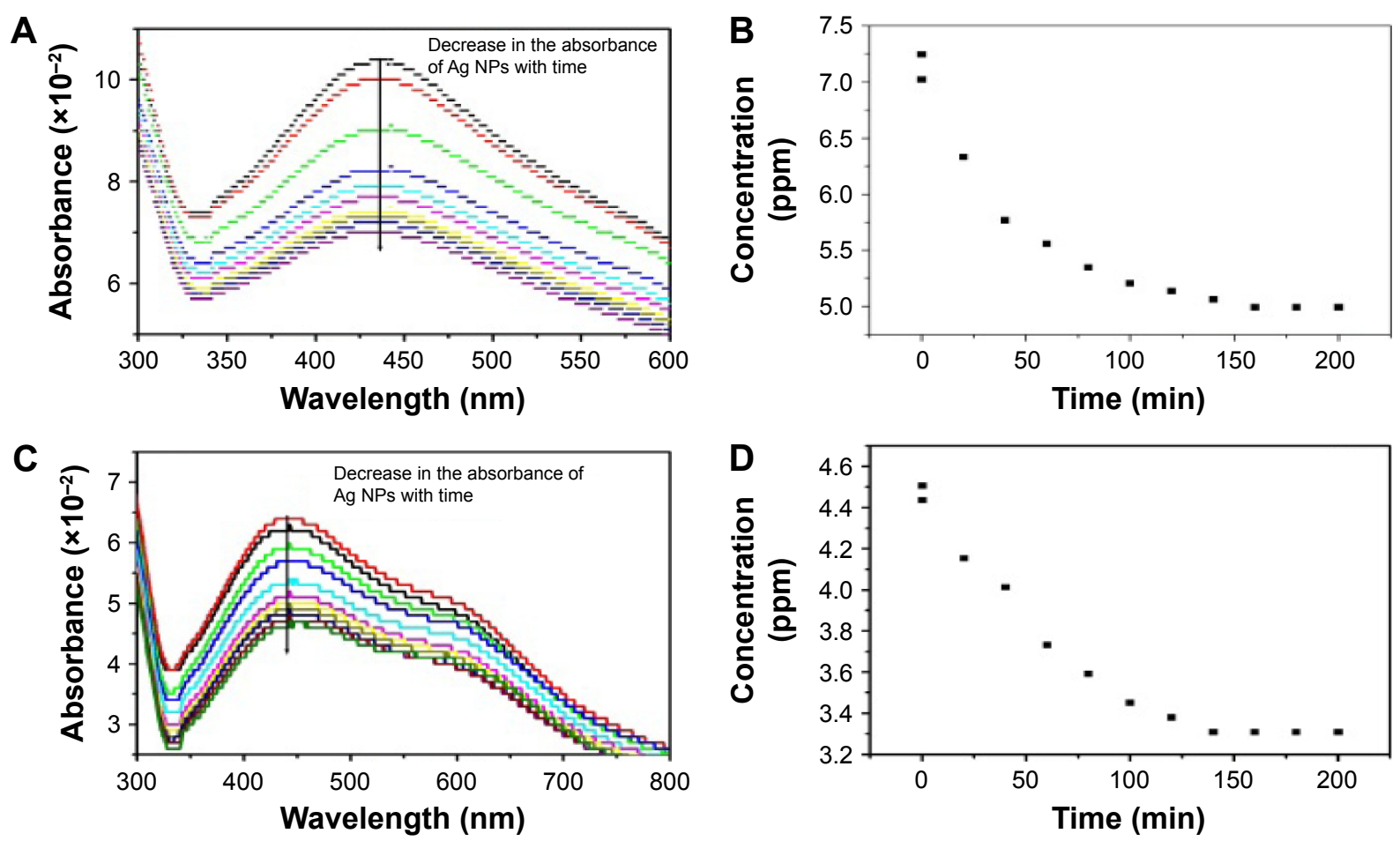

Figure 2 Ultra - visible absorption spectra of $\mathrm{Ag}$ and $(\mathbf{A})$ chlorpyrifos and $(\mathbf{C})$ malathion with time. Concentration change of $\mathrm{Ag}$ nanoparticles with respect to (B) chlorpyrifos and (D) malathion with time.

Abbreviation: NPs, nanoparticles.

After about $180 \mathrm{~min}$, the optical absorption is reduced to a large extent. The dampening of the intensity of the original plasmon could be due to the adsorption of chlorpyrifos on the nanoparticles surface. At this stage, the solution turned pale blue and the pesticide-adsorbed nanoparticles began to precipitate. Figure $2 \mathrm{~B}$ shows the change in the concentration of Ag nanoparticles with time with respect to chlorpyrifos.

Figure $2 \mathrm{C}$ shows the changes in the optical absorption spectrum of Ag nanoparticles when interacted with 1 ppm malathion at different intervals of time. Similar procedure was repeated as in the case of chlorpyrifos. Figure 2D shows the change in the concentration of Ag nanoparticles with time with respect to malathion.

IR spectra of solution II were taken just after mixing Ag nanoparticles with pesticides and also after $200 \mathrm{~min}$ (Figure 3). Clearly, the pesticide peaks at 1,245 and 1,374 $\mathrm{cm}^{-1}$ diminished with time. These peaks are identified as $\mathrm{C}-\mathrm{N}$ stretch related to aromatic amines present in chlorpyrifos.
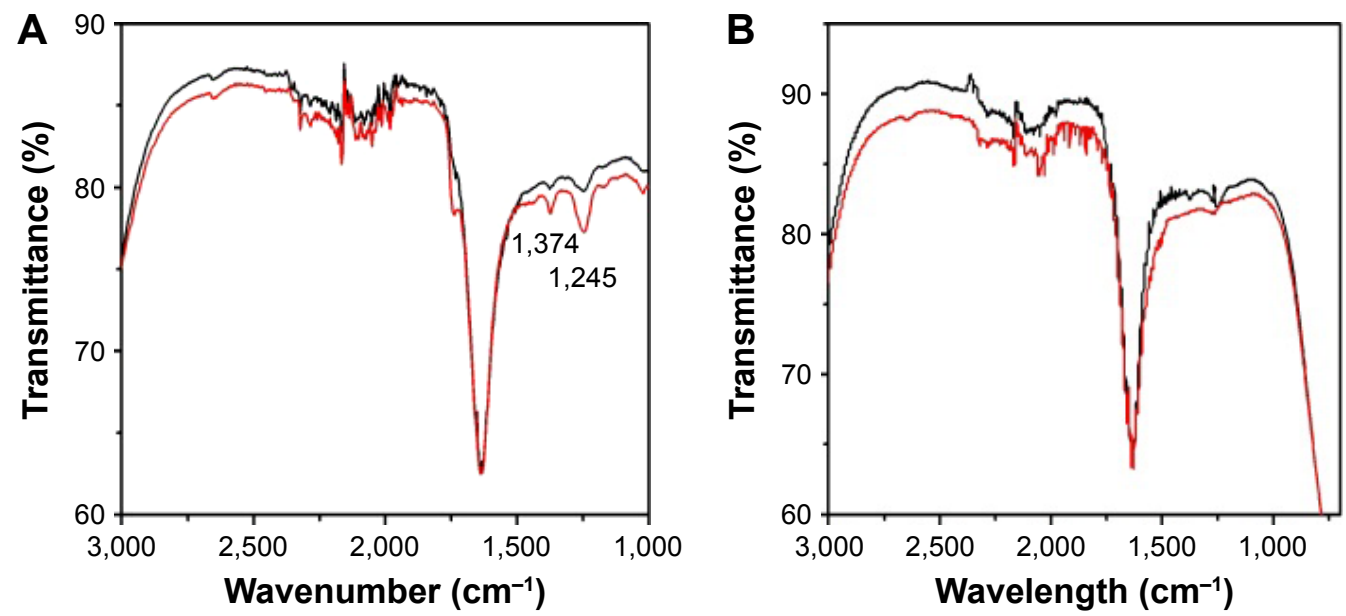

Figure 3 Infrared spectra of (A) chlorpyrifos and (B) malathion before (red line) and after the adsorption (black line) on Ag nanoparticles over a period of 200 min. 

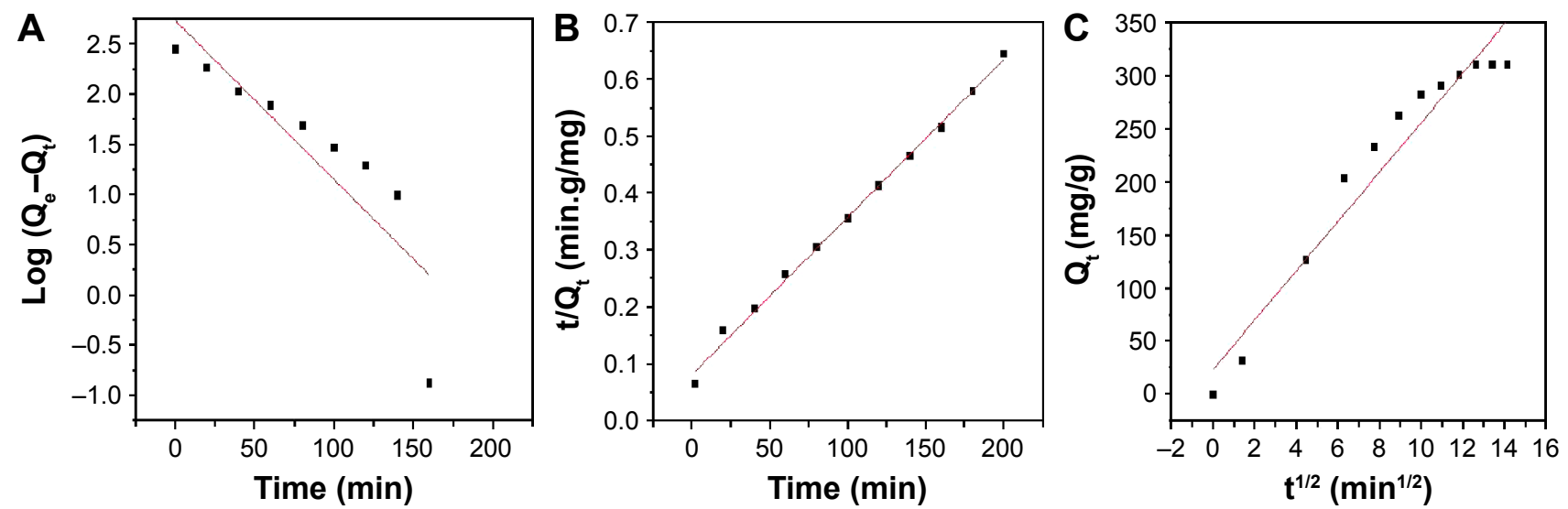

Figure 4 Kinetic models of adsorption for chlorpyrifos - pseudo-first-order (A), pseudo-second-order (B), and intraparticle diffusion kinetic plot $(\mathbf{C})$ at $25^{\circ} \mathrm{C}$.

Hence, the pesticides were absorbed by the nanoparticles via $\mathrm{C}-\mathrm{N}$ linkage. Malathion pesticide does not have $\mathrm{C}-\mathrm{N}$ bond. Thus, it is unlikely to get adsorbed over $\mathrm{Ag}$ nanoparticles.

\section{Adsorption kinetics}

To understand which absorption model is followed, kinetic studies were done. For the kinetics of the adsorption of chlorpyrifos and malathion over $\mathrm{Ag}$ nanoparticles, we assumed that the decrease in the concentration of $\mathrm{Ag}$ nanoparticles was directly proportional to the decrease in the pesticide concentration. Thus, the value of decrease in absorbance of $\mathrm{Ag}$ nanoparticles at $\lambda_{\max } 430 \mathrm{~nm}$ was related to the pesticide concentration. First, the amount of pesticide absorbed into unit weight of $\mathrm{Ag}$ nanoparticles (adsorbent), $\mathrm{Q}_{\mathrm{e}}$ in $\mathrm{mg} \mathrm{mg}^{-1}$ (equilibrium uptake), was calculated from the mass balance equation $\mathrm{Q}_{\mathrm{e}}=\left(\mathrm{C}_{0}-\mathrm{C}_{\mathrm{e}}\right) \mathrm{V} \mathrm{m}^{-1}$. Now, in order to evaluate the kinetics, pseudo-first-order, pseudo-second-order, and intraparticle diffusion models were tested by using rate equations: $\log \left(\mathrm{Q}_{\mathrm{e}}-\mathrm{Q}_{\mathrm{t}}\right)=\log \mathrm{Q}_{\mathrm{e}}-\left(\mathrm{k}_{1} / 2.303\right) \mathrm{t}, \mathrm{t} / \mathrm{Q}_{1}=1 / \mathrm{k}_{2} \mathrm{Q}_{\mathrm{e}}^{2}+\mathrm{t} / \mathrm{Q}_{\mathrm{e}}$, and $\mathrm{Q}_{1}=\mathrm{k}_{\mathrm{i}} \mathrm{t}^{1 / 2}+\mathrm{C}$ for pseudo-first-order, pseudo-second-order, and intraparticle diffusion, respectively.

Figure 4 shows the plot of all the three models and parameter $\mathrm{k}_{1}$ for chlorpyrifos. $\mathrm{Q}_{\mathrm{e}}$ and the correlation coefficient $\left(R^{2}\right)$ values were also determined from the fitting (Table 1).

From all the above data, best-fit straight line was obtained between $\mathrm{t} / \mathrm{Q}_{\mathrm{t}}$ versus $\mathrm{t}\left(R^{2}=0.99574\right)$. Hence, the adsorption of chlorpyrifos on Ag nanoparticles followed the pseudosecond-order kinetic model.

Figure 5 shows the plot of all the three models and parameter $\mathrm{k}_{1}$ for malathion. $\mathrm{Q}_{\mathrm{e}}$ and the correlation coefficient $\left(R^{2}\right)$ values were also determined from the fitting (Table 2).

From all the above data, best-fit straight line was obtained between $\mathrm{Q}_{1}$ versus $\mathrm{t}^{1 / 2}\left(R^{2}=0.94695\right)$. Hence, the adsorption of malathion on $\mathrm{Ag}$ nanoparticles followed the interparticle diffusion.
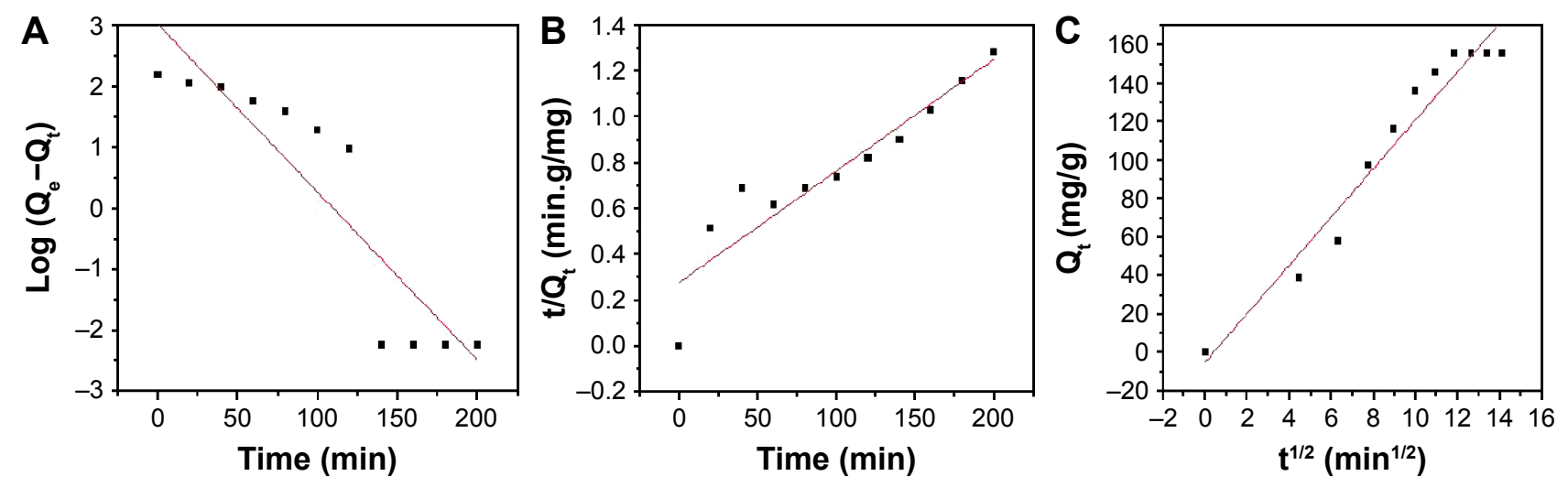

Figure 5 Kinetic models of adsorption for malathion - pseudo-first-order (A), pseudo-second-order (B), and intraparticle diffusion kinetic plot $(\mathbf{C})$ at $25^{\circ} \mathrm{C}$. 
Table I Kinetic parameters for the adsorption of chlorpyrifos on $\mathrm{Ag}$ nanoparticles

\begin{tabular}{lll}
\hline Models & Model coefficients & $R^{2}$ \\
\hline Pseudo-first-order & $\mathrm{Q}_{\mathrm{e}}=540.82 \mathrm{mg} \mathrm{mg}^{-1}$ & 0.72993 \\
& $\mathrm{~K}_{\mathrm{l}}=0.0364 \mathrm{~min}^{-1}$ & \\
Pseudo-second-order & $\begin{array}{l}\mathrm{Q}_{\mathrm{e}}=361.0101 \mathrm{mg} \mathrm{mg}^{-1} \\
\mathrm{~K}_{2}=9.35 \times 10^{-5} \mathrm{mg} \mathrm{mg}^{1} \mathrm{~min}^{-1}\end{array}$ & 0.99574 \\
Intraparticle diffusion & $\mathrm{K}_{\mathrm{l}}=23.2112 \mathrm{mg} \mathrm{mg}^{-1} \mathrm{~min}^{-1}$ & 0.94039 \\
& $\mathrm{C}=24.5046 \mathrm{mg} \mathrm{mg}^{-1}$ & \\
\hline
\end{tabular}

\section{Conclusion}

Chlorpyrifos has better affinity to Ag nanoparticles compared with malathion due to the aromatic amine group present in chlorpyrifos as evidenced by IR. Different kinetic models are followed by chlorpyrifos and malathion. While chlorpyrifos follows second-order kinetic, malathion follows interparticle diffusion. This study makes Ag nanoparticles a better choice to remove chlorpyrifos from the drinking water. For malathion, Ag nanoparticles are not very active.

\section{Acknowledgments}

This work was supported by the National Science Foundation and the Environmental Protection Agency under Cooperative Agreement DBI-0830117. Department of Chemistry and Biochemistry, and Materials Department, University of California, Santa Barbara, are gratefully acknowledged.
Table 2 Kinetic parameters for the adsorption of malathion on Ag nanoparticles

\begin{tabular}{lll}
\hline Models & Model coefficients & $R^{2}$ \\
\hline Pseudo-first-order & $\begin{array}{l}\mathrm{Q}_{\mathrm{e}}=1,049.06 \mathrm{mg} \mathrm{mg}^{-1} \\
\mathrm{~K}_{\mathrm{l}}=0.0633 \mathrm{~min}^{-1}\end{array}$ & $0.8052 \mathrm{I}$ \\
Pseudo-second-order & $\begin{array}{l}\mathrm{Q}_{\mathrm{e}}=204.918 \mathrm{mg} \mathrm{mg}^{-1} \\
\mathrm{~K}_{2}=8.53 \times 10^{-5} \mathrm{mg} \mathrm{mg}^{-1} \mathrm{~min}^{-1}\end{array}$ & 0.85879 \\
Intraparticle diffusion & $\mathrm{K}_{\mathrm{i}}=12.5724 \mathrm{mg} \mathrm{mg}^{-1} \mathrm{~min}^{-1}$ & 0.94659 \\
& $\mathrm{C}=4.4648 \mathrm{mg}$ & \\
\hline
\end{tabular}

\section{Disclosure}

The authors report no conflicts of interest in this work.

\section{References}

1. Petrosius SC, Drago RS, Young V, Grunewald GC. Low-temperature decomposition of some halogenated hydrocarbons using metal oxide/ porous carbon catalysts. $J$ Am Chem Soc. 1993;115:6131-6137.

2. Ichinose N. Superfine Particle Technology. Berlin, Germany: Springer; 1992.

3. Dyer SM, Cattani M, Pisaniello DL, Williams FM, Edwards JW. Peripheral cholinesterase inhibition by occupational chlorpyrifos exposure in Australian termiticide applicators. Toxicology. 2001;169:177-185.

4. Zeljezic D, Garaj-Vrhovac V. Sister chromadit exchange and proliferative rate index in the longitudinal risk assessment of occupational exposure to pesticides. Chemosphere. 2002;46:295-303.

5. Priester JH, Singhal A, Wu B, Stucky GD, Patricia A. Integrated approach to evaluating the toxicity of novel cysteine-capped silver nanoparticles to Escherichia coli and Pseudomonas aeruginosa. Analyst. 2014;139:954-963.
International Journal of Nanomedicine

\section{Publish your work in this journal}

The International Journal of Nanomedicine is an international, peerreviewed journal focusing on the application of nanotechnology in diagnostics, therapeutics, and drug delivery systems throughout the biomedical field. This journal is indexed on PubMed Central, MedLine, CAS, SciSearch ${ }^{\circledR}$, Current Contents ${ }^{\circledR} /$ Clinical Medicine,

\section{Dovepress}

Journal Citation Reports/Science Edition, EMBase, Scopus and the Elsevier Bibliographic databases. The manuscript management system is completely online and includes a very quick and fair peer-review system, which is all easy to use. Visit http://www.dovepress.com/ testimonials.php to read real quotes from published authors. 